\title{
Animation - AR Silhouette Model to Create Character Identity Innovation for Computer Art Pre-Production
}

\author{
Wannaporn Chujitarom, Chaiporn Panichruttiwong
}

Rangsit University, Pathumthani, Thailand

\begin{abstract}
The research objectives are: (1) to develop an Animation-AR (AAR) Silhouette Model to Create Character Identity Innovation for Computer Art PreProduction; (2) to evaluate the model; and (3) to study the effect of using the model. The sample group are 7 experts who have taught computer art for more than 5 years. The results of the research were: (1) the model consists of 3 elements: Input Factors, AAR Silhouette Process, and Character Identity Innovation; (2) the result of a satisfaction model based on expert assessment is at the highest level $(\overline{\mathrm{x}}=4.33$, S.D. $=0.69)$; and (3) the results of the trial using the model found that the Character Identity Innovation displays a high level of satisfaction.
\end{abstract}

Keywords - Computer Art, AR, Animation, Character, Silhouette, Pre-Production, Innovation.

\section{Introduction}

Today's world is driven by innovation. The computer art industry, which includes movie making, animation, games, websites, and much more, has to adjust the production technology to meet the needs of the world, for example, program and application innovations that can replace human labor. Such innovations will also save time and reduce costs.

DOI: 10.18421/TEM94-55

https://doi.org/10.18421/TEM94-55

Corresponding author: Wannaporn Chujitarom,

Rangsit University, Pathumthani, Thailand.

Email: wannaporn.c@rsu.ac.th

Received: 14 September 2020.

Revised: 01 November 2020.

Accepted: 07 November 2020.

Published: 27 November 2020.

(c) BY-NC-ND (C) 2020 Wannaporn Chujitarom \& Chaiporn Panichruttiwong; published by UIKTEN. This work is licensed under the Creative Commons AttributionNonCommercial-NoDerivs 4.0 License.

The article is published with Open Access at www.temjournal.com
Computer Art refers to all types of art, while computer technology is an essential part of the creative process. This process can involve pictures, sounds, animations, games, websites, and animations [1].

AR refers to augmented reality in computer graphics. It works in the form of collaboration between graphics processing and real world images obtained from cameras. It is one of the hottest technologies today, as it can combine the real world with the virtual world. As a result, it can create more participation situations for players. It is also used in many other areas such as marketing, tourism and education [2]. An animation in the form of AR adds a lot of interest to the content, as it will result in players feeling more engaged, and will create more fun and make the topic under consideration more understandable. AR Animation is currently popular. For example, by using an application for AR animation in an AR Animation learning material book, when the reader shines a light on the book, the characters will appear to move, and the reader can see all directions when the books is used in conjunction with a tablet or smart phone [3].

Animation is an aspect of the computer art that is created by still images cascading together into animation, both in 2D and 3D, until finally being developed into a 4D format [4]. Supporting the imagination of humans that cannot be created by the shooting of movies or can be better conveyed with animation, it also uses themes of light, sound, story and characters, making it more engaging than normal content [5]. Therefore, animation is popularly applied to industries such as film, education, travel and marketing. In addition, various animation formats such as VR and AR technology, etc. have been developed to increase its appeal and functionality.

Animation involves a number of production processes, namely Pre-Production, Production and Post-Production [6].

Pre-Production is the process of thinking about Concept, Theme, Story, Script, Storyboard and Character. 
Production is the process of filming. This involves creating animations or starting creating characters with the use of computer art programs [7].

Post-Production is the editing process in which special effects, video and audio sequences are added, and the final result is recorded as a work of computer art [8].

Character Design is a step in the process of PreProduction. This is very important as it acts as a guide for the story, and determines whether or not the audience is interested in following the story depending as a result of their interest in the characters. Character Identity is an easilyrecognizable feature of a character. As a result, the audience can remember name and features of that character. Character identity is of great importance to the computer art and animation industries. This is because, when the audience clearly remember a character, they can maintain an interest in that character and may then purchase the character's work, including animations, toys, and merchandise. Character design elements include function, style and personality. There are several ways to create a character's identity, one of the more popular of which is to use Silhouette [9].

Silhouette is the outline, or shadow of the character's shape. Silhouette is the main factor that makes our characters attractive and memorable. Observers tend to remember the outline of characters rather than the details [10] [11]. An example of a famous character is Walt Disney's Mickey Mouse. Its silhouette is that of a mouse with extra-large ears and standing on two legs. We can see that even a black shadow could allow us to recognize that character. Such an outline is the key to success in character design. Outlines are also commonly used in character pose design. This is because work on posture design helps the posture to be more beautiful and interesting. A good silhouette should look memorable, interesting and unique [9].

Innovation is something that is new and beneficial to the economy and to society [12]. Innovation is an essential tool for driving the economy and industry. Innovation can give rise to new technologies which save time and reduce production costs, and reduces the effort which humans have to make. It brings many benefits to both the economy and society. The components of innovation are: 1. Originality; 2. Economic or Social Benefits; and 3. Knowledge and Creativity [13].

In this research, the researchers combined animation and AR technology in the form of Animation-AR (AAR) to test the use of Silhouette to create an innovative character's identity to promote computer art in the pre-production phase. This was done by using an application that can bring three Silhouette Character designs to life. All three characters will be able to move like a complete animation. The researchers then let the experts assess the satisfaction they obtained from the AnimationAR (AAR) Silhouette Model and the results of the character innovation.

\section{Objectives}

The research objectives are: (1) to develop an Animation-AR Silhouette Model to Create Character Identity Innovation for Computer Art PreProduction; (2) to evaluate the model; and (3) to study the results of the experimental model.

\section{Research Scope}

The sample consisted of seven experts, all of whom worked as lecturers in the computer art, animation, character design and AR fields, and all of whom had at least five years' experience. They were selected with the use of a purposive sampling. The research tools were Likert scale, arithmetic mean, standard deviation and a scoring rubric.

\section{Research Framework}

The independent variables were Animation, AR, Computer Art, Pre-Production, Character, Silhouette, Innovation and the AAR Silhouette Model. The dependent variable was the Character Identity Innovation (See Figure 1).

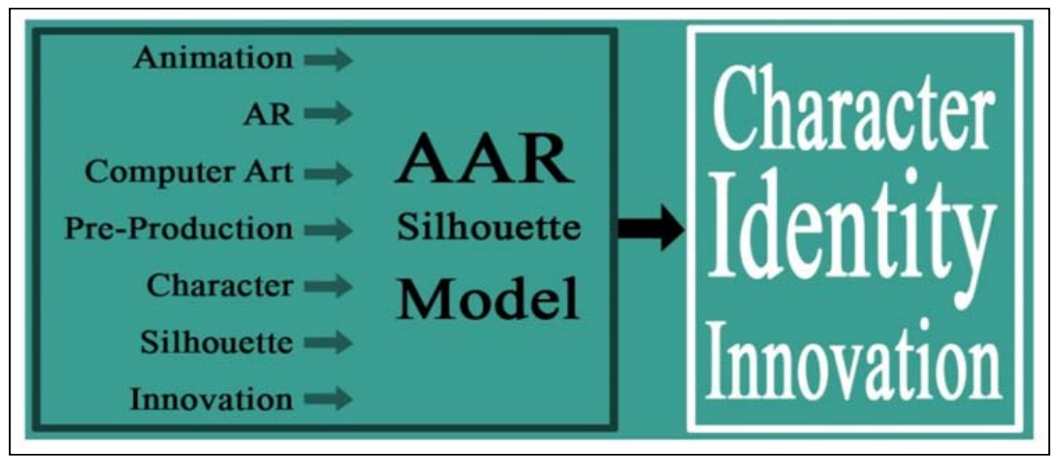

Figure 1. Research Framework 


\section{Research Methodology}

The research methodology can be divided into four parts:

Part 1 is the development of an AAR Silhouette Model to create character identity innovation for computer art pre-production. The process consists of: 1. studying the theory and related research; 2 . analyzing and synthesizing a research framework; 3 . designing and developing the AAR Silhouette model as a diagram.

Part 2 is the evaluation of the AAR Silhouette Model. This is done by creating research tools to measure satisfaction with the model. This involves using a five levels Likert scale consisting of 'Strongly agree', 'Agree', 'Neither agree nor disagree', 'Disagree' and 'Strongly disagree'. The model is then submitted to 7 experts in order to assess the degree of satisfaction with the model and to provide additional recommendations. All the assessors work as lecturers in computer art, animation, character design and AR and had at least five years' experience. The purposive sampling method was used to choose the assessors.

In Part 3 the synthetic model is tested with the help of the group of 7 experts. A character designed for the 4th RSU Cartoon Idea Contest was introduced as a research case study. This contest was held by Rangsit University in Thailand to act as a platform for an international cartoon ideas contest. Originally, the character used as a mascot for this contest was a dog with a light bulb conveying ideas. But for the $4^{\text {th }}$ contest, the mascot was changed to a new character in the form of a mouse. However, to keep the original identity of the contest, the light bulb was still used. The researcher made the main character to be a mouse, which is the symbol of the 2020 zodiac, and then created a total of 3 different silhouettes.

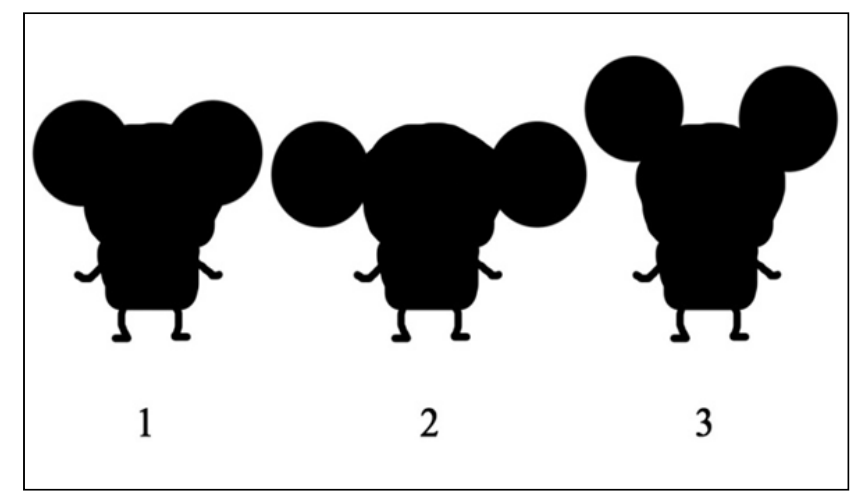

Figure 2. 3 Different Character Silhouettes

The three silhouettes were then applied to the Animation-AR Application via the RakugakiAR application, to create an animated character silhouette. Once this had been accomplished, the experts were asked to choose the best version for use as a mascot for the competition.

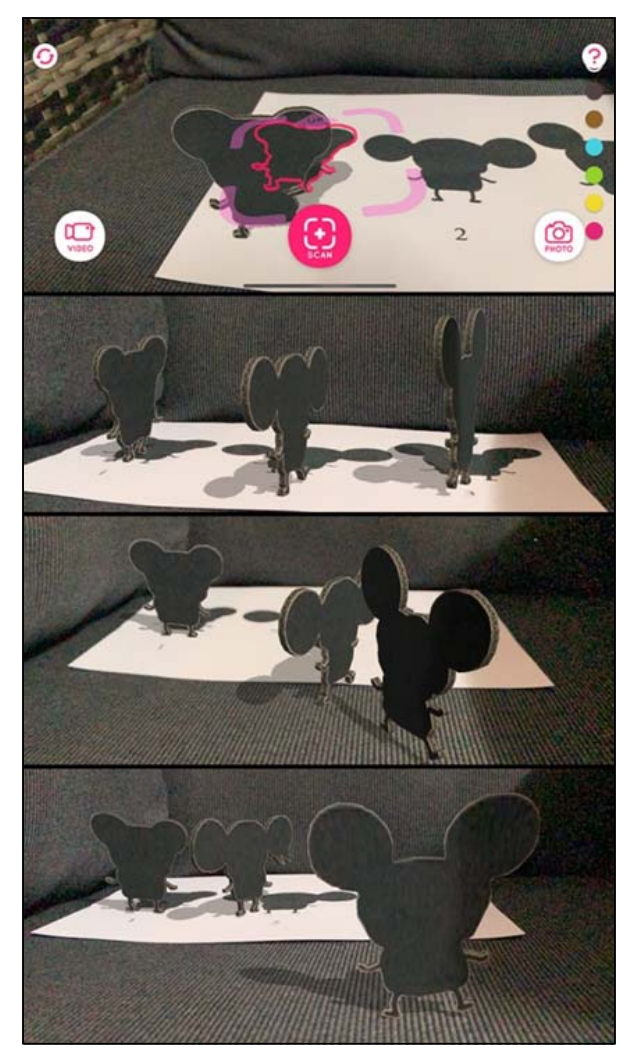

Figure 3. Animation-AR Silhouette via Application

In this part, it was necessary to determine the most beautiful, practical and outstanding character silhouette. Only the best one was to be developed into the final character. In this case silhouette number 3 was judged to be the best. This was because it had the most distinctive features. In contrast, number 1 was not attractive, and number 2 had too much clutter when moving around. This approach takes into account the most memorable, interesting, unique and time-saving characteristics, to create a measure of innovation in character creation with the AAR Silhouette Model to create character identity innovation for computer art pre-production.

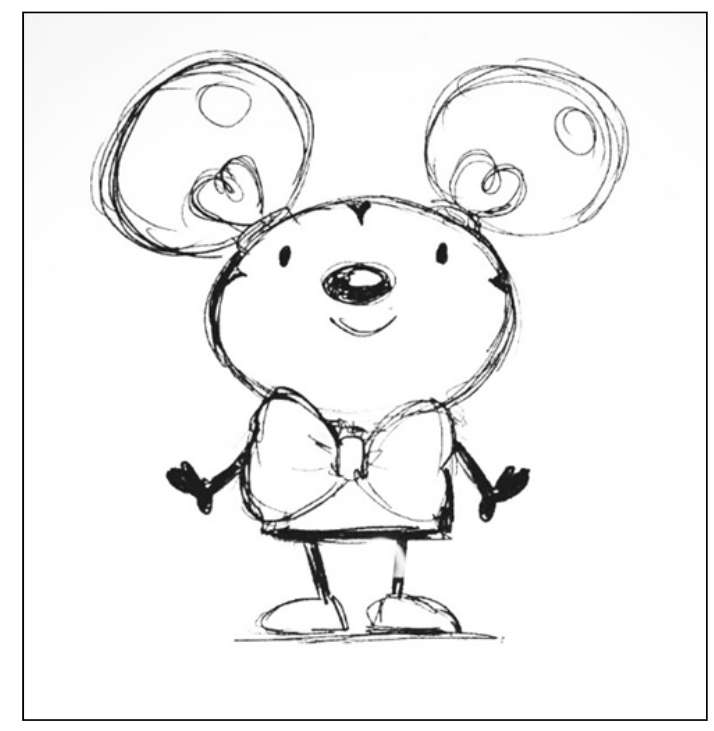

Figure 4. Final Character from the Best Silhouette 
Part 4 involves taking the best character silhouette for expert evaluation. The research tool for this section is a rubric table with 4 topics: memorable, interesting, unique and time-saving. In terms of the rubric score, each topic has 3 points, divided into 4 items: 0 point, 1 point, 2 points and 3 points.

Table 1. Rubric Score

\begin{tabular}{|c|c|c|c|c|}
\hline Topic/Points & 0 & 1 & 2 & 3 \\
\hline Memorable & None & Average & Good & $\begin{array}{c}\text { Very } \\
\text { Good }\end{array}$ \\
\hline Interesting & None & Average & Good & $\begin{array}{c}\text { Very } \\
\text { Good }\end{array}$ \\
\hline Unique & None & Average & Good & $\begin{array}{c}\text { Very } \\
\text { Good }\end{array}$ \\
\hline Save Time & None & Average & Good & $\begin{array}{c}\text { Very } \\
\text { Good }\end{array}$ \\
\hline
\end{tabular}

Once all 7 experts have seen AAR silhouette process and character design work, then score it through the rubric table score.

\section{Findings}

The findings of the research were divided into 4 parts:

Part 1 is the Animation-AR Silhouette Model to Create Character Identity Innovation for Computer Art Pre-Production, has 3 elements, consisted of Input Factor, AAR Silhouette Process and Character Identity Innovation.

Input Factors, is a character design element, which is function, style and personality. These three elements are integral to character design.

AAR Silhouette Process involves 3 important processes: Character Silhouette, Animation-AR Application and Animated Character. The following work procedures are included: Start by creating at least 3 designed character silhouette. Then bring the Animation-AR application to use, it will become a character that can move and move around. In this way, you can see which silhouette will be the most suitable for the character.

Character Identity Innovation, is the procedure for measuring innovation results consisting of memorable, interesting, unique and save time. See the diagram in Figure 5.

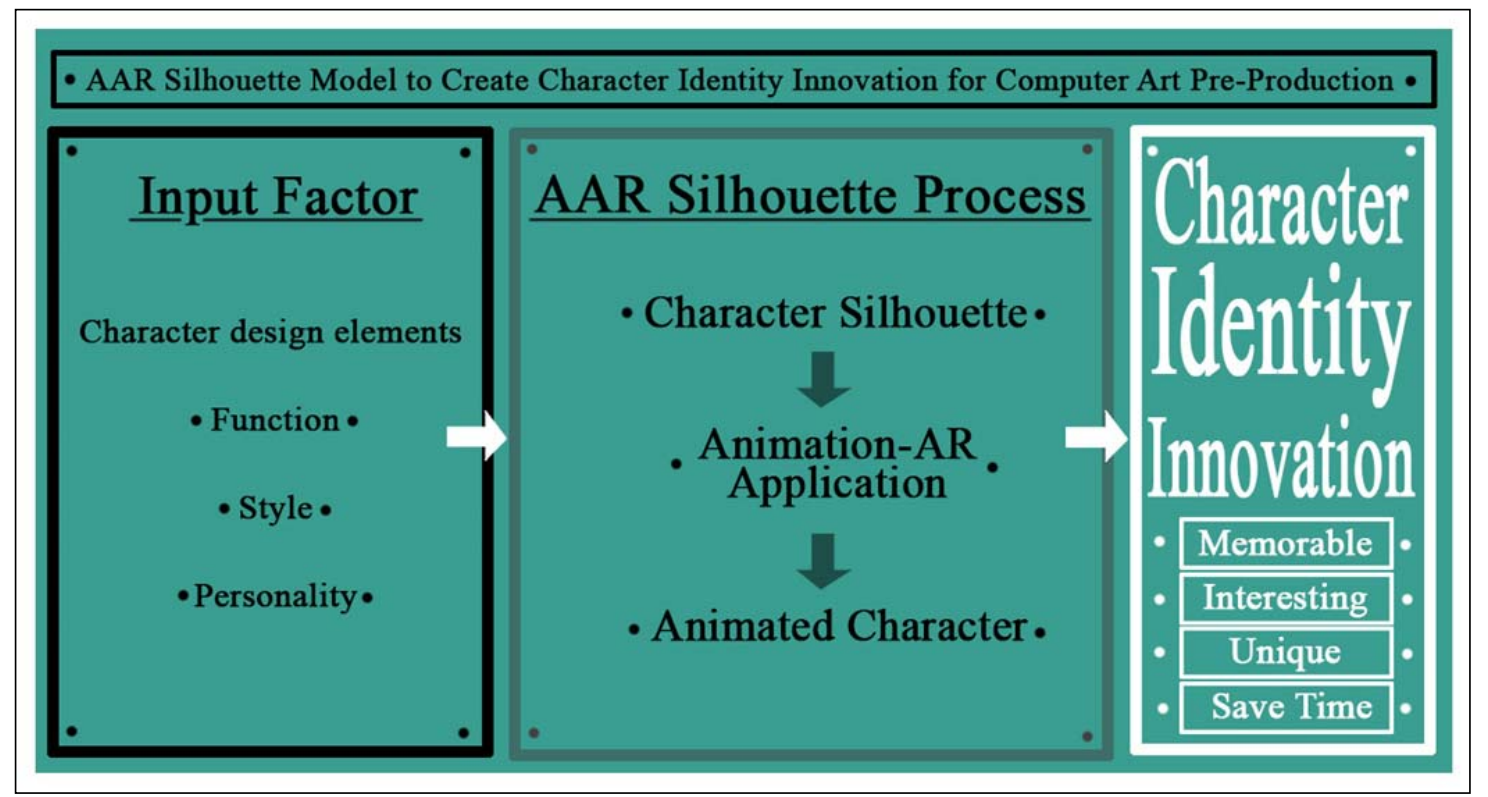

Figure 5. Animation-AR Silhouette Model to Create Character Identity Innovation for Computer Art Pre-Production

Part 2 is the result of an assessment in terms of satisfaction on the part of the 7 experts all of whom are teachers who teach in computer art field with at least 5 years of experience. The tool used in this research was a Likert scale involving five levels of measurement: 'Strongly agree', 'Agree', 'Neither agree nor disagree', 'Disagree' and 'Strongly disagree'. Suitability was assessed through analysis using the mean $(\bar{x})$ and standard deviation (S.D.). The criteria for suitability were as follows: 1.00-1.80 indicates lowest, 1.81-2.60 indicates low, 2.61-3.40 indicates medium, 3.41-4.20 indicates high and 4.21-5.00 indicates highest levels of satisfaction. The results of this expert evaluation are as follows: All 7 experts agreed that the developed model was at the highest and most appropriate level $(\overline{\mathrm{x}}=4.33$, S.D. $=0.69)$ : Input Factor $(\overline{\mathrm{x}}=4.14$, S.D. $=0.67)$; AAR Silhouette Process $(\overline{\mathrm{x}}=4.38$, S.D. $=0.69)$; and Character Identity Innovation $(\overline{\mathrm{x}}=4.46$, S.D. $=0.71)$. (See Table 2). 
Table 2. Arithmetic mean and standard deviation results from 7 experts

\begin{tabular}{|lccc|}
\hline Components & $\mathbf{( \mathbf { x } )}$ & $\mathbf{( S . D . )}$ & Suitability \\
Elements 1: & & & \\
Input Factor & & & \\
Function & 4.28 & 0.75 & Highest \\
Style & 4.14 & 0.69 & Highest \\
Personality & 4.00 & 0.57 & \\
Sum of Elements 1 & 4.143 & 0.67 & Highest \\
Elements 2: & & & \\
AAR Silhouette & & & \\
Process & & & \\
Character Silhouette & 4.28 & 0.48 & Highest \\
Animation-AR & 4.42 & 0.78 & Highest \\
Application & 4.42 & 0.78 & Highest \\
Animated Character & 4.38 & 0.68 & Highest \\
Sum of Elements 2 & & & \\
Elements 3: & & & \\
Character Identity & & & \\
Innovation & 4.57 & 0.53 & Highest \\
Memorable & 4.28 & 0.75 & Highest \\
Interesting, & 4.42 & 0.78 & Highest \\
Unique & 4.57 & 0.78 & \\
Save time & 4.46 & 0.71 & Highest \\
Sum of Elements 3 & 4.33 & 0.69 & Highest \\
Results & & & \\
\hline
\end{tabular}

Part 3 is the model implementation. In the case study of character design for an international contest, the $4^{\text {th }}$ RSU Cartoon Idea Contest, held by Rangsit University in Thailand, acted as a platform for an international cartoon ideas contest. The process begins with assigning a character that will be used as a mascot for the contest, taking into account function, style and personality, which are the input factors in character design. A mouse was chosen as the mascot for the 2020 Zodiac Year. The AAR Silhouette Process was then started by creating three different mouse silhouettes with different ear positions. Differences in the position of the ears can highlight the character. This takes place in the Character Silhouette step. Next is Animation-AR application, when the 3 different silhouettes were loaded into RakugakiAR application. This allowed the silhouette character to come alive in that it was able to move around as an animation within a real environment, as an Animation-AR. As a result of the Animated Character step, when the silhouette character is able to move around, the audience will be able to determine which one is the most attractive and practical. In the third element - Character Identity Innovation - silhouette number 3 was chosen as the best for developing into the final mascot character, in that it was the most attractive with a big and high ear position silhouette. The final mascot character was completed with the details of the eyes, mouth, nose, body and costume being added. The seven experts were then asked to assess all stages of the formation, and to express their satisfaction with the complete character.

Part 4 involved the results of the expert assessment of the character identity innovation. All 7 experts assessed the procedure using the rubric table in terms of the following topics: being memorable, interesting, unique and time saving for the pre-production process. The criteria for character identity innovation were as follows: $0.00-1.00$ indicates low, 1.01-2.00 indicates medium, 2.01-3.00 indicates high. All of them concluded that the characters scored at the highest level. The results are as shown in Table 3.

Table 3. Character Identity Innovation Evaluation

\begin{tabular}{|lccc|}
\hline Topic & $\mathbf{( \overline { \mathbf { x } } )}$ & $\mathbf{( S . D . )}$ & Suitability \\
Memorable & 2.42 & 0.78 & High \\
Interesting & 2.71 & 0.48 & High \\
Unique & 2.71 & 0.48 & High \\
Save Time & 2.71 & 0.48 & High \\
Results & 2.64 & 0.56 & High \\
\hline
\end{tabular}

All 7 experts agreed that the Character Identity Innovation was at the high appropriate level $(\bar{x}=2.64$, S.D. $=0.56)$. Specifically, it was Memorable $(\overline{\mathrm{x}}=2.42$, S.D. $=0.78)$; Interesting $(\overline{\mathrm{x}}=2.71$, S.D. $=0.48)$; Unique $(\overline{\mathrm{x}}=2.71$, S.D. $=0.48)$; and Time Saving $(\overline{\mathrm{x}}=$ 2.71, S.D. $=0.48$ )

\section{Discussion}

All 7 experts agreed that an AAR silhouette model to create character identity innovation for computer art pre-production was at the highest appropriate level $(\overline{\mathrm{x}}=4.33$, S.D. $=0.69)$. In addition, the Character Identity Innovation was of the highest level $(\bar{x}=2.64$, S.D. $=0.56)$. The findings are consistent with Papaefthymiou et al. (2017), which supports the use of AR technology and others to promote character creation [14]. It is also consistent with the findings of Hui Ye et al. (2020) which indicated that using AR animation makes character design better and easier [15]. The findings also relate to those of Barakonyi and Schmalstieg (2006), in terms of introducing AR technology to promote character animation design [16].

\section{Conclusions}

Animation-AR Silhouette Model to create character identity innovation for computer art preproduction, contains 3 elements: Input Factor, AAR Silhouette Process and Character Identity Innovation.

Input Factors is a character design element, which involves function, style and personality.

In the AAR Silhouette Process, there are 3 important processes: Character Silhouette, Animation-AR Application and Animated Character. 
Character Identity Innovation is the procedure for measuring innovation results. This consists of memorable, interesting, unique and time saving characteristics.

Seven experts agreed that the AAR Silhouette model for creating character identity innovation for computer art pre-production, is the most suitable approach available, and scores at the highest level.

In terms of the results of the case study incorporating the experimental AAR Silhouette Model, it was found that the seven experts involved were satisfied with the high level of character identity innovation.

From the research results, it can be concluded that the introduction of animation and AR technologies can be used to promote character design with regard to using a silhouette. It also promotes the characters by making them memorable, interesting and unique, and saves production time in terms of the preproduction process of animation.

Finally, this character design identity innovation is suitable for experimenting with character design in the animation industry. It is also suitable for use in teaching and learning character design, computer art, digital art, and animation as part of a short course or a university program.

\section{References}

[1]. Mealing, S. (2007). Computers and Art: Computers and Art. Intellect Books.

[2]. Jung, T., tom Dieck, M. C., \& Rauschnabel, P. A. (Eds.). (2020). Augmented Reality and Virtual Reality: Changing Realities in a Dynamic World. Springer Nature.

[3]. Chujitarom, W., \& Piriyasurawong, P. (2017). Animation Augmented Reality Book Model (AAR Book Model) to Enhance Teamwork. International Education Studies, 10(7), 59-64.

[4]. Sito, T. (2013). Moving innovation: a history of computer animation. MIT press.

[5]. Winder, C. and Dowlatabadi, Z. (2001). Producing Animation. FocalPress, Burlington.

[6]. Lord, P., \& Sibley, B. (1998). Creating 3-D Animation: The Aardman Book of Filmmaking, Harry N. Abrams. Inc., New York, NY.

[7]. Kerlow, I. V. (2009). The art of 3D computer animation and effects. John Wiley \& Sons.

[8]. Wales, L. M. (2017). The complete guide to film and digital production: the people and the process. Taylor $\&$ Francis.

[9]. Panichruttiwong, C. (2020). Character Design for Computer Art. Rangsit University Press.

[10]. Sloan, R. J. S. (2015). Virtual character design for games and interactive media. CRC Press.

[11]. Maestri, G. (2006). Digital character animation 3. New Riders.

[12]. Larkley, J. E., \& Maynhard, V. B. (2008). Innovation in education. Nova Publishers.

[13]. Popadiuk, S., \& Choo, C. W. (2006). Innovation and knowledge creation: How are these concepts related?. International journal of information management, 26(4), 302-312.

[14]. Papaefthymiou, M., Kateros, S., Georgiou, S., Lydatakis, N., Zikas, P., Bachlitzanakis, V., \& Papagiannakis, G. (2017). Gamified AR/VR character rendering and animation-enabling technologies. In Mixed Reality and Gamification for Cultural Heritage (pp. 333-357). Springer, Cham.

[15]. Ye, H., Kwan, K. C., Su, W., \& Fu, H. (2020). ARAnimator: in-situ character animation in mobile AR with user-defined motion gestures. ACM Transactions on Graphics (TOG), 39(4), 83-1.

[16]. Barakonyi, I., \& Schmalstieg, D. (2006). Augmented reality in the character animation pipeline. In $A C M$ SIGGRAPH 2006 Sketches (pp. 75-es). 